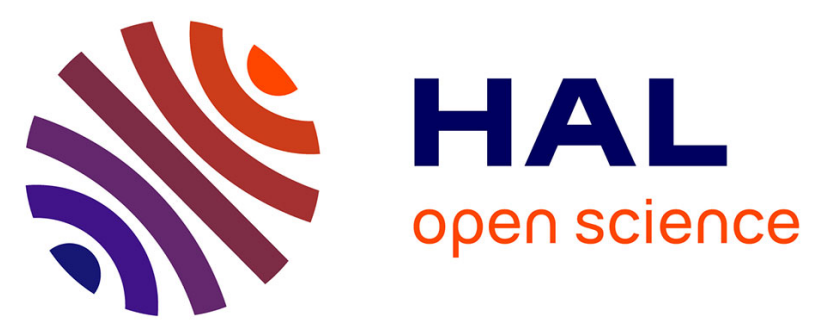

\title{
Cerebrospinal fluid interleukin (IL)-10 and IL-10:IL-6 ratio as biomarkers for small B-cell lymphoproliferations with leptomeningeal dissemination
}

Myrto Costopoulos, Rathana Kim, Sylvain Choquet, Karim Maloum, Caroline Houillier, Caroline Algrin, Catherine Settegrana, Juliette Villemonteix, Martine Brissard, Claire Quiney, et al.

\section{To cite this version:}

Myrto Costopoulos, Rathana Kim, Sylvain Choquet, Karim Maloum, Caroline Houillier, et al.. Cerebrospinal fluid interleukin (IL)-10 and IL-10:IL-6 ratio as biomarkers for small Bcell lymphoproliferations with leptomeningeal dissemination. Seminars in Hematology, 2017, 10.1053/j.seminhematol.2017.06.005 . hal-01590965

\section{HAL Id: hal-01590965 \\ https://hal.sorbonne-universite.fr/hal-01590965}

Submitted on 20 Sep 2017

HAL is a multi-disciplinary open access archive for the deposit and dissemination of scientific research documents, whether they are published or not. The documents may come from teaching and research institutions in France or abroad, or from public or private research centers.
L'archive ouverte pluridisciplinaire HAL, est destinée au dépôt et à la diffusion de documents scientifiques de niveau recherche, publiés ou non, émanant des établissements d'enseignement et de recherche français ou étrangers, des laboratoires publics ou privés. 


\section{CSF IL-10 and IL-10:IL-6 ratio as biomarkers for small B-cell lymphoproliferations with leptomeningeal dissemination}

Myrto Costopoulos ${ }^{1,2,3^{*}}$, Rathana $\mathrm{Kim}^{1^{*}}$, Sylvain Choquet $^{4}$, Karim Maloum ${ }^{1}$, Caroline Houillier $^{5}$, Caroline Algrin ${ }^{4}$, Catherine Settegrana ${ }^{1}$, Juliette Villemonteix ${ }^{1}$, Martine Brissard ${ }^{1}$, Claire Quiney ${ }^{1}$, Sophie Bernard ${ }^{6}$, Frederic Davi ${ }^{1,2,3}$, Catherine Thieblemont ${ }^{6}$, Khe HoangXuan $^{2,5}$, Veronique Leblond ${ }^{2,4}$, Helene Merle-Beral ${ }^{1,2,3}$ and Magali Le Garff-Tavernier ${ }^{1,3}$

*These authors equally contributed to this work.

${ }^{1}$ Department of Biological Hematology, Pitie-Salpetriere Hospital, 47-83 Boulevard de l'hopital, 75013 Paris, France

${ }^{2}$ Sorbonne Universités, UPMC, Paris 6, 91-105 Boulevard de l'hopital, 75013 Paris, France

${ }^{3}$ Centre de Recherche des Cordeliers, INSERM UMRS 1138, Cell Death and Drug Resistance in Lymphoproliferative Disorders, 15 rue de l'ecole de medecine, 75005 Paris, France

${ }^{4}$ Department of Clinical Hematology, Pitie-Salpetriere Hospital, 47-83 Boulevard de l'hopital, 75013 Paris, France

${ }^{5}$ Department of Neuro-Oncology, Pitie-Salpetriere Hospital, 47-83 Boulevard de 1'hopital, 75013 Paris, France

${ }^{6}$ APHP, Saint-Louis hospital, Hemato-oncology department \& Paris Cité Sorbonne Diderot 7 University, 1 avenue Vellefaux, 75010 Paris, France 
Corresponding author: Myrto Costopoulos, Department of Biological Hematology, PitieSalpetriere Hospital, 47-83 Boulevard de l'hopital, 75013 Paris, France myrto.costopoulos@aphp.fr

Financial Support: None.

Conflict of interest: the authors have no conflict of interest to declare.

All authors approved the manuscript and this submission. 
Identifying the etiology of neurological symptoms in blood malignancies is still a challenging issue. Lymphomatous meningitis (LM) is mainly described in aggressive systemic lymphomas (diffuse large B-cell (DLBCL) and Burkitt lymphomas) [1, 2]. Leptomeningeal involvement in small B-cell lymphoproliferative disorders (CLPD) is a rare, poorly described condition, only mentioned in a few case-reports [3, 4]. The diagnosis is suspected in patients presenting non-specific central nervous system (CNS) symptoms and non-specific results on medical imaging. It is confirmed by the detection of tumor cells in the cerebrospinal fluid (CSF). At present, conventional cytology (CC) can confirm the diagnosis for high tumor burden with excellent specificity but its sensitivity remains low. During the past decade, flow cytometry analysis (FCM) has been reported as a highly sensitive tool to detect lymphomatous cells. To overcome early cell mortality, the adjunction of a stabilizing cell solution to CSF can be used [5]. Unfortunately, these tests are not always efficient enough to diagnose LM. New complementary approaches are required. Soluble biomarkers seem to be potent candidates since they can be processed using multiplex techniques on quite small volumes; hence overcoming cellular pitfalls. Among the various screened candidates, interleukin (IL)-10 is promising[6, 7]. It is a pleiotropic, anti-inflammatory, cytokine involved in B-cell differentiation. This marker has been largely used to diagnose primary vitreoretinal lymphoma (PVRL) $[8,9]$. More recently, its role in primary CNS lymphoma (PCNSL) and systemic DLBCL with CNS involvement has been documented [10-13]. It has also been proposed in dual with IL-6 level to determine the IL-10:IL-6 ratio [7, 14]. The aim of our study was to evaluate the diagnostic value of IL-10 and IL-6 levels combined with the IL10:IL-6 ratio in CSF in CLPD with LM. 
Thirty patients were recruited over 4 years from the two hematology centers in Paris: Pitie Salpetriere and Saint Louis university hospitals. All patients suffered from small B-cell LM: 7 chronic lymphocytic leukemias (CLL), 6 mantle-cell lymphomas (MCL), 14 Waldenström macroglobulinemias (WM), 1 follicular lymphoma (FL), and 2 unclassified Bcell non-Hodgkin lymphomas (u B-NHL). All patients presented CNS symptoms and medical imaging was evocative of an LM. Leptomeningeal dissemination was revealed by CC, FCM or immunoglobulin heavy chain rearrangement analyses (IGHV), before intrathecal chemotherapy, either at the diagnostic stage or at the time of the relapse. IL-10 and IL-6 were measured by the Cytometric Bead Array® technique (human IL-10 and IL-6 CBA kits; BD Biosciences $^{\mathrm{TM}}$, Pont de Claix, France) on a FACSCantoII flow cytometer (BD Biosciences ${ }^{\mathrm{TM}}$ ) following the manufacturer's recommendations. This method is correlated with the standard sandwich enzyme immunoassay (ELISA) technique [7] and the limit of sensitivity is 2.5 $\mathrm{pg} / \mathrm{ml}$. Data were analyzed on the FACSDiva software (BD Biosciences ${ }^{\mathrm{TM}}$ ). This is a retrospective medical record review study performed with approval from the Pitie-Salpetriere hospital committee. All existing data were processed without any additional tests and were treated confidentially.

Patients were mostly male (male:female ratio of 2) with a median age of 71 (range [49-88]). Notably, IL-10 levels were generally low. Indeed, approximately half of the patients $(\mathrm{n}=17)$ had an undetectable IL-10 level $(<2.5 \mathrm{pg} / \mathrm{ml})$ along with undetectable or low levels of IL-6 [2.5-14 pg/ml], leading to an IL-10:IL-6 ratio <1 or undeterminable (group ${ }^{\circ} 1$ ). All the other patients had detectable IL-10 levels [4-39 pg/ml] with heterogeneous levels of IL-6 [4$540 \mathrm{pg} / \mathrm{ml}$ ( table). The IL-10 cutoffs previously described in three studies on PCNSL and DLBCL with LM fluctuated (3, 9.5 and $16.5 \mathrm{pg} / \mathrm{ml})$ [10, 11, 13, 15]. Therefore, IL-10 level is not enough as an isolated marker for aggressive lymphomas with LM. We applied the IL- 
10:IL-6 ratio with a threshold set at 1, as described in PRVL[9], to divide patients into 2 additional subgroups: group $n^{\circ} 2$ with ratios $\leq 1(n=9)$ and group $n^{\circ} 3$ with ratios $>1(n=4)$. In the vast majority of the patients, CLPD with LM were associated with an IL-10:IL-6 ratio of $\leq 1$ (groups $\mathrm{n}^{\circ} 1$ and $\mathrm{n}^{\circ} 2$ ). All these patients with ratios IL-10:IL-6 $\leq 1$ presented CLPD with LM, but no evidence of aggressive B-cell lymphoma. Surprisingly, even in patients with MCL which is considered to be an aggressive lymphoma, IL-10:IL-6 ratios in the CSF were still low. Interestingly, in WM patients with LM ( $\mathrm{n}=14)$, also called Bing Neel syndrome[16], IL-6 levels tend to be higher (median value: $7.5 \mathrm{pg} / \mathrm{ml}$ ) than in CLL (median value: $4 \mathrm{pg} / \mathrm{ml}$ ) and MCL patients (median value: $4.5 \mathrm{pg} / \mathrm{ml}$ ). The $2 \mathrm{WM}$ patients who had the highest cell count in the CSF (\#25 and 26) also presented the highest IL-6 levels. High levels of IL-6 in the CSF could be an additional argument for BNS as IL-6 plays a central role in the WM microenvironment[17]. Moreover, further investigations on IL-6 levels seem to be interesting in BNS to examine its role in WM pathophysiology. Group $\mathrm{n}^{\circ} 3$ includes patients suffering from both CLPD and another aggressive lymphoma. Two patients had PCNSL simultaneously diagnosed in the CSF. For patient \#29, these results were confirmed by the IGHV analysis on the brain biopsy and the CSF, showing 2 different tumoral clones. Patient \#27 presented a blastoid variant of MCL. Patient \#30 had a transformed WM into DLBCL in the CNS during follow-up. Additionally, these 4 patients also presented an increased IL-10 level ( $\geq 10 \mathrm{pg} / \mathrm{ml})$ (table). Furthermore, an elevated IL-10 level associated with an IL-10:IL-6 ratio >1 occurring in patient with indolent lymphoma LM should potentially require further investigations to detect any concomitant large B-cell lymphoma, as revealed by our cohort. In these difficult cases, the contribution of IGHV analysis could be essential to confirm the co-existence of multiple tumoral clones. Other soluble biomarkers such as CXCL13 [10], soluble CD19 [18] or soluble CD23 [19] could be relevant in this context. 
In conclusion, we here report for the first time that low levels of IL-10 do not exclude LM in CLPD. Unexpectedly, IL-10 levels and IL-10:IL-6 ratio in CLPD differed from the levels observed in DLBCL. We report the usefulness of adding the IL-10:IL-6 ratio in order to potentially reveal more aggressive lymphomas: either a transformation or an association with another "hidden" lymphoma such as PCNSL. 


\section{$\underline{\text { References }}$}

1. Kridel R\&Dietrich PY Prevention of ens relapse in diffuse large b-cell lymphoma. Lancet Oncol 2011;12:1258-66.

2 Perkins AS\&Friedberg JW Burkitt lymphoma in adults. Hematology Am Soc Hematol Educ Program 2008;341-8.

3 Moazzam AA, Drappatz J, Kim RY\&Kesari S Chronic lymphocytic leukemia with central nervous system involvement: Report of two cases with a comprehensive literature review. J Neurooncol 2012;106:185-200.

4 Simon L, Fitsiori A, Lemal R, et al. Bing-neel syndrome, a rare complication of waldenstrom macroglobulinemia: Analysis of 44 cases and review of the literature. A study on behalf of the french innovative leukemia organization (filo). Haematologica 2015;100:1587-94.

5 Quijano S, Lopez A, Manuel Sancho J, et al. Identification of leptomeningeal disease in aggressive b-cell non-hodgkin's lymphoma: Improved sensitivity of flow cytometry. Journal of clinical oncology : official journal of the American Society of Clinical Oncology 2009;27:1462-9.

6 Korfel A, Nowosielski M, Pardo-Moreno J, et al. How to facilitate early diagnosis of cns involvement in malignant lymphoma. Expert review of hematology 2016;9:1081-91.

7 Fisson S, Ouakrim H, Touitou V, et al. Cytokine profile in human eyes: Contribution of a new cytokine combination for differential diagnosis between intraocular lymphoma or uveitis. PLoS One 2013;8:e52385.

8 Costopoulos M, Touitou V, Golmard JL, et al. Isold: A new highly sensitive interleukin score for intraocular lymphoma diagnosis. Ophthalmology 2016;

9 Chan CC, Whitcup SM, Solomon D\&Nussenblatt RB Interleukin-10 in the vitreous of patients with primary intraocular lymphoma. Am J Ophthalmol 1995;120:671-3.

10 Rubenstein JL, Wong VS, Kadoch C, et al. Cxcl13 plus interleukin 10 is highly specific for the diagnosis of cns lymphoma. Blood 2013;121:4740-8.

11 Sasagawa Y, Akai T, Tachibana O\&lizuka H Diagnostic value of interleukin-10 in cerebrospinal fluid for diffuse large b-cell lymphoma of the central nervous system. J Neurooncol 2015;121:177-83.

12 Nguyen-Them L, Costopoulos M, Tanguy ML, et al. The csf il-10 concentration is an effective diagnostic marker in immunocompetent primary cns lymphoma and a potential prognostic biomarker in treatment-responsive patients. Eur J Cancer 2016;61:69-76.

13 Song $Y$, Zhang W, Zhang L, et al. Cerebrospinal fluid il-10 and il-10/il-6 as accurate diagnostic biomarkers for primary central nervous system large b-cell lymphoma. Sci Rep 2016;6:38671.

14 Whitcup SM, Stark-Vancs V, Wittes RE, et al. Association of interleukin 10 in the vitreous and cerebrospinal fluid and primary central nervous system lymphoma. Arch Ophthalmol 1997;115:115760 .

15 Sasayama T, Nakamizo S, Nishihara M, et al. Cerebrospinal fluid interleukin-10 is a potentially useful biomarker in immunocompetent primary central nervous system lymphoma (pcnsl). Neuro Oncol 2012;14:368-80.

16 Minnema MC, Kimby E, D'Sa S, et al. Guideline for the diagnosis, treatment and response criteria for bing-neel syndrome. Haematologica 2017;102:43-51.

17 Elsawa SF, Novak AJ, Ziesmer SC, et al. Comprehensive analysis of tumor microenvironment cytokines in waldenstrom macroglobulinemia identifies ccl5 as a novel modulator of il-6 activity. Blood 2011;118:5540-9.

18 Muniz C, Martin-Martin L, Lopez A, et al. Contribution of cerebrospinal fluid scd19 levels to the detection of cns lymphoma and its impact on disease outcome. Blood 2014;123:1864-9. 
19 Grelier A, Le Garff-Tavernier M, Nauwelaers F, Sarfati M\&Merle-Beral H Soluble cd23 measurement by cba: $A$ convenient and reliable quantification method in chronic lymphocytic leukemia. Cytometry B Clin Cytom 2014;86:91-7. 
$\underline{\text { Table }}$

Patient clinical characteristics and CSF data

BNS: Bing Neel syndrome, CC: conventional cytology, CLL: lymphocytic leukemia, FCM:

flow cytometry, FL: follicular lymphoma, IGHV: immunoglobulin heavy chain variable region genes, IL: interleukin, MCL: mantle-cell lymphomas, NP: not performed, PCNSL: primary central nervous system lymphoma, u B-NHL: unclassified B-cell non-Hodgkin lymphoma, WBC: white blood cells count, WM: Waldenström macroglobulinemia 


\begin{tabular}{|c|c|c|c|c|c|c|c|c|c|}
\hline Groups & Patients & Diagnosis & $\mathrm{WBC} / \mathrm{mm}^{3}$ & $\overline{\mathrm{CC}}$ & FCM & IGHV & $\begin{array}{c}\text { IL-10 } \\
(\mathrm{pg} / \mathrm{ml})\end{array}$ & $\begin{array}{c}\text { IL-6 } \\
(\mathrm{pg} / \mathrm{ml})\end{array}$ & IL-10:IL-6 ratio \\
\hline \multirow{17}{*}{1} & \#1 & CLL & 10 & - & + & + & $<2.5$ & $<2.5$ & Undeterminable \\
\hline & \#2 & CLL & 0 & - & + & + & $<2.5$ & $<2.5$ & Undeterminable \\
\hline & \#3 & CLL & 0 & - & + & + & $<2.5$ & $<2.5$ & Undeterminable \\
\hline & \#4 & MCL & 6 & - & + & + & $<2.5$ & $<2.5$ & Undeterminable \\
\hline & \#5 & WM (BNS) & 7 & - & + & - & $<2.5$ & $<2.5$ & Undeterminable \\
\hline & \#6 & WM (BNS) & 0 & - & - & + & $<2.5$ & $<2.5$ & Undeterminable \\
\hline & \#7 & CLL & 30 & - & + & + & $<2.5$ & 7 & $<1$ \\
\hline & \#8 & CLL & 2 & - & + & $N P$ & $<2.5$ & 14 & $<1$ \\
\hline & \#9 & MCL & 3 & - & + & $N P$ & $<2.5$ & 5 & $<1$ \\
\hline & \#10 & WM (BNS) & 0 & - & + & + & $<2.5$ & 3 & $<1$ \\
\hline & \#11 & WM (BNS) & 3 & + & - & + & $<2.5$ & 4 & $<1$ \\
\hline & \#12 & WM (BNS) & 1 & + & + & + & $<2.5$ & 4 & $<1$ \\
\hline & \#13 & WM (BNS) & 0 & - & + & $N P$ & $<2.5$ & 9 & $<1$ \\
\hline & \#14 & CLL & 14 & - & + & - & $<2.5$ & 4 & $<1$ \\
\hline & \#15 & MCL & 0 & - & + & + & $<2.5$ & 4 & $<1$ \\
\hline & \#16 & WM (BNS) & 4 & - & + & $N P$ & $<2.5$ & 10 & $<1$ \\
\hline & \#17 & MCL & 2 & - & - & + & $<2.5$ & 12 & $<1$ \\
\hline \multirow{9}{*}{2} & $\# 18$ & MCL & 0 & - & - & + & 3 & 3 & $<1$ \\
\hline & \#19 & FL & 24 & + & - & - & 3 & 4 & $<1$ \\
\hline & \#20 & CLL & 15 & + & + & + & 3 & 5 & $<1$ \\
\hline & \#21 & u B-NHL & $>100$ & + & + & $N P$ & 4 & 4 & 1 \\
\hline & \#22 & WM (BNS) & 32 & + & + & + & 4 & 11 & $<1$ \\
\hline & \#23 & WM (BNS) & 5 & - & + & $N P$ & 5 & 8 & $<1$ \\
\hline & \#24 & WM (BNS) & 38 & - & + & + & 7 & 32 & $<1$ \\
\hline & \#25 & WM (BNS) & $>100$ & + & + & $N P$ & 36 & 540 & $<1$ \\
\hline & \#26 & WM (BNS) & $>100$ & + & + & $N P$ & 39 & 359 & $<1$ \\
\hline \multirow{4}{*}{3} & $\# 27$ & $\mathrm{MCL}$ & $>100$ & + & + & + & 24 & 5 & $>1$ \\
\hline & \#28 & u B-NHL + PCNSL & 0 & - & + & $N P$ & 10 & $<2.5$ & $>1$ \\
\hline & \#29 & $\mathrm{WM}(\mathrm{BNS})+\mathrm{PCNSL}$ & 1 & - & + & + & 18 & 4 & $>1$ \\
\hline & \#30 & Transformed WM & 6 & + & + & $N P$ & 21 & 7 & $>1$ \\
\hline
\end{tabular}

